\title{
USO DA MEMBRANA PLASMÁTICA E PAREDE CELULAR COMO ALVOS PARA NOVOS AGENTES ANTIFÚNGICOS: UMA REVISÃO
}

\author{
A.F. OLIVEIRA $^{1}$, E. R. SOUZA ${ }^{1}$ e L. N. ARAÚJO NETO ${ }^{1}$
}

${ }^{1}$ Universidade Federal de Pernambuco, Centro Biociências, Departamento de Antibióticos, Laboratório de Química e Inovação Terapêutica.

E-mail para contato: arianyfrana@hotmail.com

RESUMO - As infecções fúngicas vêm se mostrando cada vez mais prejudiciais a saúde pública devido a elevação de registros, resistência, incidência em imunodeprimidos e aos problemas medicamentosos. Este artigo tem o objetivo de verificar os recentes avanços na busca por alvos farmacológicos visando o desenvolvimento de novos antifúngicos. Uma revisão de literatura com base em artigos indexados ao Science Direct, PubMed e Scielo, publicados entre 2012 e 2017, pesquisados utilizando as palavras-chaves: fungal inhibition, antifungal therapy, antifungal target, antifungal mechanism, antifungal effect e antifungal activity. Foram relatados estruturas especificas e inespecificas presentes na membrana plasmática e parede celular, mesmo sendo envoltórios já utilizados na clínica médica, sua complexidade permite que novos alvos sejam descobertos. Abordou-se também, alvos relacionados ao sistema redox. Nesta revisão, observou-se diferentes áreas das ciências da saúde, biologia e biotecnologia convergindo no estudo de novos agentes antifúngicos que atuem sobre alvos em diversas regiões e componentes celulares do fungo, sendo a seletividade o principal desafio. A literatura aponta uma reação da ciência ao crescimento das complicações e reforça os avanços promissores para o fortalecimento do arsenal terapêutico antifúngico.

Palavras-chave: antifúngico; alvo farmacológico; membrana celular; parede celular

ABSTRACT - Fungal infections have been shown to be increasingly harmful to public health due to increased records, resistance, immunocompromised incidence, and drug problems. This article aims to verify the recent advances in the search for pharmacological targets aiming the development of new antifungals. A review of the literature based on articles indexed to Science Direct, PubMed and Scielo, published between 2012 and 2017, searched using the keywords: fungal inhibition, antifungal therapy, antifungal target, antifungal mechanism, antifungal effect and antifungal activity. Specific and nonspecific structures present in the plasma membrane and cell wall have been reported, even though they are wraps already used in the medical clinic, their complexity allows new targets to be discovered. It was also approached, targets related to the redox system. In this 
review, we observed different areas of health sciences, biology and biotechnology converging in the study of new antifungal agents that act on targets in diverse regions and cellular components of the fungus, being the selectivity the main challenge. The literature points to a reaction of science to the growth of complications and reinforces the promising advances for the strengthening of the antifungal therapeutic arsenal.

Keyworks: antifungal; pharmacological target; cell membrane; cell wall.

\section{INTRODUÇÃO}

As infecções fúngicas têm grande importância epidemiológica considerando seus registros em todo planeta e as problemáticas que estão envolvidas no tratamento, podendo resultar na ineficácia do mesmo e contribuir para a elevada taxa de mortalidade (Pemán e Quindós, 2015). Na maioria dos casos, as IFI são oportunistas pelo fato de acometerem pacientes com nível de vulnerabilidade imunológica elevado causado por oncopatologias, síndrome da imunodeficiência adquirida (Sida/VIH), doenças autoimunes e medicamentos imunossupressores (Del Principe et al., 2016; Lin et al., 2015; Fernández-Ruiz et al., 2016). Esse estado de vulnerabilidade colabora para o surgimento de infecções oportunistas e exige a administração de medicamentos adicionais ao tratamento principal do paciente, aumentando a incidência de efeitos colaterais e adversos, sobrecarregando seu organismo e comprometendo o resultado final do esquema terapêutico, podendo levar a óbito (FernándezRuiz et al., 2016; Mezzari et al., 2013).

Tendo em vista todos os problemas que incidem na terapia antifúngica, o desenvolvimento de novos fármacos é necessário. Utilizando o conhecimento fisiológico dos fungos, receptores ainda não utilizados na clínica médica estão sendo identificados e estudados com o objetivo de elaborar compostos fungicidas e fungistáticos mais eficientes, potentes, seletivos, não tóxicos, com melhores propriedades farmacocinéticas e farmacotécnicas, como também driblar a resistência fúngica (Kathiravan et al., 2012; Rabelo et al., 2016). Estes estudos poderão contribuir para o fortalecimento do arsenal terapêutico, trazendo maior eficiência no tratamento medicamentoso das infecções fúngicas, por tanto, este artigo tem o objetivo de verificar os recentes avanços na pesquisa de estruturas fúngicas que atuem como alvos farmacológicos visando o desenvolvimento de novas classes terapêuticas contra micoses.

\section{MATERIAIS E MÉTODOS}

Este estudo baseou-se em uma revisão de literatura cuja pesquisa bibliográfica foi realizada mediante a busca eletrônica de artigos científicos indexados nas bases de dados ScienceDirect, National Center for Biotechnology Information - U.S. National Library of Medicine (PubMed) e e Scientific Electronic Library Online (Scielo). Após consulta aos Descritores em Ciências da Saúde (DeCS), identificaram-se as palavras-chaves: fungal inhibition, target antifungal therapy, plasma membrane, antifungal mechanism, cell wall $e$ oxidative stress. A pesquisa considerou os artigos publicados entre os anos de 2012 a 2017, incluindo-se publicações no idioma inglês. Foram lidos previamente os resumos dos artigos ou o texto completo, quando necessário, para avaliar abrangência. Foram utilizadas as 
referências que se identificaram com o objetivo do estudo. Uma vez escolhidos os artigos, iniciou-se a análise e síntese dos mesmos com uma leitura exploratória para reconhecimento dos artigos que interessavam à pesquisa de forma geral; uma leitura seletiva para selecionar os que seriam usados no estudo; uma leitura analítica dos selecionados e por último a leitura interpretativa com o intuito de conferir um significado mais amplo aos resultados escolhidos para uma melhor elaboração textual.

\section{RESULTADOS E DISCUSSÃO}

\section{Membrana Plasmática}

A membrana plasmática (MP) dos fungos é amplamente utilizada como alvo terapêutico, inclusive há fármacos comerciais que atuam sobre ela ou na sua biossíntese. Essa se caracteriza por ser o principal envoltório celular e responsável por muitas funções importantes. Possui inúmeros constituintes particulares que lhe conferem singularidades e, consequentemente, a torna um local de ação terapêutica extremamente relevante. Dessa maneira, a MP ainda é uma estrutura com potencial para novas terapias antifúngicas (Sant et al., 2016).

Entre estes constituintes estão diversos lipídios (glicerofosfolipídeos, esfingolípidos e esteróis), e proteínas (transportadoras, transdutoras, ATPases, e sintetases) (Douglas et al., 2016). Muitos grupos de pesquisa investigam a ação de compostos contra fungos e a relacionam com alterações exercida sobre a MP, mesmo que o mecanismo exato não esteja elucidado. Um dos principais efeitos descrito como responsável pela morte fúngica através da membrana é a formação de poros, que como consequência aumenta a permeabilidade levando o fungo a morte (Sant et al., 2016; Yun et al., 2017; Choi et al., 2014; Lee at al., 2014). No arsenal antifúngico atualmente disponível, a anfotericina B também tem a capacidade de formar poros na MP. Entretanto isso se deve a sua interação com o ergosterol de membrana (Ciesielski et al., 2016). Um estudo realizado com diferentes espécies de fungos patogênicos objetivou investigar a ação do fitoquímico Silymarin, este com concentrações antifúngicas entre 2,5 e 10,0 $\mu \mathrm{g} / \mathrm{mL}$, e verificou-se que sua atuação ocorreu por perturbação da MP através de diferentes testes. No primeiro ensaio, foi analisado o influxo de iodeto de propídeo em $C$. albicans, corante fluorescente de difícil penetração na MP e ligante do DNA, que aumentou 10, 18 e 30\% quando tratadas nas concentrações de 5,0,10,0 e 20,0 $\mu \mathrm{g} / \mathrm{mL}$, respectivamente (Yun et al., 2017).

Outro teste utilizou um modelo de membrana lipídica artificial, construindo grandes vesículas unilamelares miméticas a MP de $C$. albicans com o intuito de encapsular calceína, substância também fluorescente. Quando as vesículas foram submetidas às concentrações $5,0,10,0$ e $20,0 \mu \mathrm{g} / \mathrm{mL}$ de Silymarin, observou-se que a calceína teve sua taxa de fuga acrescida em 31,53 e $56 \%$ respectivamente. Ainda utilizando o mesmo modelo membranoso, foi analisado a fuga de fluoresceína isotiocianato-dextrano (FD) de diferentes pesos moleculares, que comprovou a formação de poros capazes de permitir a penetração de moléculas menores a 3,3 nm (Yun et al., 2017).

A formação de poros na MP também foi relacionada à ação antifúngica do hidrocloreto de poli-hexametileno guanidina (PHMGH) através de testes que também utilizaram vesículas membranosas artificiais similares a MP de C. albicans contendo 
diferentes FD (Choi et al., 2016 B). O PHMGH facilitou o efluxo de aproximadamente $60 \%$ da FD4 (1,4 nm), 40\% da FD10 (2,3 nm), 10\% da FD20 (3,3 nm) e 5,5\% da FD40 $(4,5 \mathrm{~nm})$, sugerindo que houve formação de poros onde a maioria tinha o tamanho entre 2,3 e 3,3 nm. Assim a MP teria boa parte de suas funções comprometidas, havendo perda de íons, despolarização e efluxo de $\mathrm{K}^{+}$(Choi et al., 2014). Enfatizando que as alterações na MP, causadas tanto pelo Silymarin quanto pelo PHMGH, foram responsáveis pela inviabilidade fúngica, os autores concluíram ainda que tais efeitos se estendem a despolarização da membrana com efluxo de $\mathrm{K}^{+}$e diminuição de sua fluidez, mas não indicaram que tais efeitos fazem qualquer relação com o ergosterol (Yun et al., 2014; Choi et al., 2016).

Um enzima importante na MP é a ATPase (MP-ATPase) ou bomba de prótons, esta exerce papel fundamental no equilíbrio eletroquímico e osmótico intracelular e a sua inibição foi associada a interrupção do crescimento de C. albican (Samber etal., 2015; Khan et al., 2012). Buscando encontrar o mecanismo antifúngico do óleo essencial de Mentha piperita (Lamiaceae) (OEM) e seus principais constituintes, estimou-se a atividade de MP-ATPase através do ensaio de efluxo de $\mathrm{H}^{+}$com e sem indução por glicose e notou-se a inibição da extrusão de $\mathrm{H}^{+}$. Quando não houve indução por glicose, o OEM inibiu 47 e $52 \%$ em cepas não resistentes e resistentes, respectivamente, já com indução de glicose ele foi capaz de inibir 44 e $38 \%$, e a inibição pelos constituintes isolados foi próxima a do OEM (Samber et al., 2015).

Em outra pesquisa, a inibição da MP-ATPase também foi relacionada com a ação antifúngica dos fitoquímicos curcumina (CUR) e $\alpha$-metil-cinamaldeído (MCD) utilizando o mesmo ensaio citado anteriormente frente a isolados padronizados-sensíveis, clínicosensíveis e clínico-resistentes de Candida spp. A CUR inibiu o efluxo de $\mathrm{H}^{+}$entre 38,83$50,37 \%$ sem glicose e 24,34-32,83\% com glicose, já o MCD inibiu entre 79,42-82,57\% sem glicose e 52,69-54,34\% com glicose, os efeitos se refletiram ainda na acidificação intracelular dos isolados ${ }^{32}$. Estes dados sugerem a MP-ATPase como um alvo terapêutico promissor principalmente para produtos naturais, pois demonstram seu potencial antifúngico sobre ela (Samber et al., 2015; Khan et al., 2012; Beauv et al., 2015).

Um perfil quimiogenômico realizado com o quitosano e diferentes mutantes de Saccharomyces cerevisiae, observou que cepas com deleções de genes envolvidos na biossíntese de esfingolípidos (ipt $1 \Delta, \operatorname{skn} 1 \Delta, l \operatorname{cb} 3 \Delta$ ), indicando que estes poderiam ser alvo para antifúngicos (Galván et al., 2013) como foi visto em estudos anteriores (Huang et al., 2010), mas as cepas de maior sensibilidade foram as que apresentaram deleções de genes envolvidos com o material nucleico (este será abordado posteriormente), dessa forma os esfingolipídios não seriam especificamente o alvo principal do quitosano, de acordo com o estudo (Galván et al., 2013).

\section{Parede Celular}

Por ser uma estrutura não presente em células de animais, a parede celular (PC) se torna naturalmente um alvo de ampla utilização na terapêutica. Para exemplificar, têmse os fármacos que atuam sobre a PC de bactérias, muito utilizados na clínica médica. A PC de alguns fungos possui quitina em sua composição, um polissacarídeo essencial que 
não está presente em células humanas e de muitos vertebrados e é responsável por sua forma, rigidez e resistência. As principais proteínas envolvidas na síntese e regulação de quitina são as quitinas sintases (QS) e a proteína quinase C (PKC) (via de sinalização) (Patel et al., 2017).

Nicomicinas e polioxinas são inibidores potentes da síntese de quitina, porém nunca foram utilizados pela medicina por não apresentarem eficácia em testes in vivo. Sendo assim, desenvolveu-se alguns análogos afim de melhorar as características moleculares e assim, torna-las clinicamente viáveis. Entretanto, não houve sucesso e nenhum deles seguiu para testes clínicos (Chaudhary et al., 2013). Neste contexto, foram planejados 20 fosforamidas derivados da cumarina, não análogas a nicomicinas e polioxinas, e avaliadas contra C. albicans, Cryptococcus neoformans, Aspergillus flavus e A. fumigatus, estas apresentaram excelentes concentrações mínimas inibitórias (CIM) que variaram entre 1 e $128 \mu \mathrm{g} / \mathrm{ml}$ (Ji et al., 2016).

Investigou-se ainda se o modo de ação das fosforamidas envolvia a inibição da QS, no qual foi observado um resultado positivo contra enzimas extraídas a partir de Candida tropcalis. Através da utilização de um conjugado de germe de trigo, que se liga a quitina emitindo fluorescência a $600 \mathrm{~nm}$, foi possível verificar que todos os compostos inibiram a QS e um deles apresentou inibição de $90 \%$, valor superior a polioxina b, fármaco padrão, que demonstrou $82 \%$ de inibição. Considerando a diferença química entre as fosforamidas participantes deste estudo e os antigos inibidores de QS, têm-se a expectativa que apresentem melhores resultados in vivo $e$ futuramente venham ser utilizadas clinicamente no tratamento de infecções fúngicas (Ji et al., 2016).

Em contrapartida, um estudo realizado com Sporotrix schenckii analisou a ação da CUR e descreveu a não inibição da biossíntese de quitina, mas sua acumulação e deslocalização. O S. schenckii foi tratado em concentração subletal de CUR (64 $\mu \mathrm{g} / \mathrm{mL})$ e analisado por reação em cadeia da polimerase (PCR) em tempo real, que mostrou influência da CUR sobre as QS 1 e 3 e a PKC, hiper-expressas 700, 10.000 e 1000 vezes, respectivamente. Este resultado sugere que a CUR possivelmente regulou a síntese de quitina através da via de sinalização $\mathrm{PKC}$, não sendo possível confirmar se o mecanismo da CUR é exatamente a acumulação, mas ofereceu evidências que indicam essa relação. A acumulação e a exposição de quitina, descrito no estudo, potencializou a depuração dos fungos e a diminuição dos fungos em camundongos, sugerindo uma baixa na virulência de S. schenckii causada pela CUR (Huang et al., 2016). Dessa forma, a perturbação da quitina e da sua biossíntese mostrou que ainda é uma área terapêutica promissora a ser explorada e vêm exibindo ótimos resultados.

A CUR foi citada em duas publicações que avaliavam sua ação sobre regiões distintas, porém ambas foram positivas (MP e parede celular). A dualidade pode ser de extrema serventia caso este composto venha a evoluir nas pesquisas e se torne um agente antifúngico utilizado clinicamente, entretanto mais estudos são necessários para esclarecer esta possibilidade (Khan et al., 2012; Huang et al., 2016). Tanto a MP quanto a parede celular caracterizam envoltórios importantes para a célula fúngica e possuem importantes pontos de interesse terapêutico, a primeira tem suas funções voltadas ao controle químico entre o meio intracelular e extracelular, já a segunda está principalmente ligada a proteção física, patogenicidade e reconhecimento celular. $\mathrm{Na}$ tabela 1 está descrito resumidamente os alvos encontrados nos envoltórios celulares abordados nesta revisão. 
Tabela 1: Alvos encontrados na MP e parede celular pesquisados para o desenvolvimento de novos antifúngicos.

\begin{tabular}{|c|c|c|c|}
\hline & ALVO & COMPOSTO & REFERÊNCIA \\
\hline \multirow{6}{*}{$\begin{array}{l}\text { Membrana } \\
\text { Plasmática }\end{array}$} & \multirow[b]{2}{*}{ Perturbação } & Silymarin & Yun et al., $2017^{26}$ \\
\hline & & $\begin{array}{l}\text { Hidrocloreto de poli-hexametileno } \\
\text { guanidina }\end{array}$ & Choi et al., 2016 \\
\hline & \multirow{3}{*}{ ATPase } & Óleo essêncial de Mentha piperita & Samber et al., 2015 \\
\hline & & Curcumina & \multirow{2}{*}{ Khan et al., 2012} \\
\hline & & $\alpha$-metil-cinamaldeído & \\
\hline & $\begin{array}{l}\text { Esfingolipídeos } \\
\text { (alvo secundário) }\end{array}$ & Quitosano & Galván et al., 2013 \\
\hline \multirow{2}{*}{$\begin{array}{l}\text { Parede } \\
\text { Celular }\end{array}$} & Quitina Sintase & Fosforamidas cumarinicas & Ji et al., 2015 \\
\hline & $\begin{array}{l}\text { Quitina: Acumulação } \\
\text { e deslocalização }\end{array}$ & Curcumina & Huang et al., 2016 \\
\hline
\end{tabular}

\section{CONCLUSÃO}

Os avanços da ciência e o enfoque dado às infecções fúngicas, devido a problemas relacionados a resistência, terapia medicamentosa e altas taxas de mortalidade, têm possibilitado o aprofundamento e direcionamento das pesquisas, contribuindo no desenvolvimento de farmacoterapias eficientes e seguras. No presente estudo, observause diferentes áreas das ciências da saúde, biologia e biotecnologia convergindo para desenvolver agentes antifúngicos que atuem nas de várias formas sobre os envoltórios celulares dos fungos. Mesmo em tempos onde a gama de conhecimento é bastante vasta, a parcela desconhecida ainda é incalculável. Existe muito a se descobrir quanto a bioquímica e fisiologia dos fungos patogênicos e sua relevância terapêutica.

\section{REFERÊNCIAS}

BEAUV UP, KONGSTAD KT, WUBSHET SG, KJELLERUP L, WINTHER AL, STAERK D. Fitoterapia Fungal plasma membrane $\mathrm{H}+$-ATPase inhibitory activity of $\mathrm{o}$ hydroxybenzylated fl avanones and chalcones from. Fitoterapia. v. 105, p. 102-106, 2015.

CHOI H, KIM KJ, LEE DG. Antifungal activity of the cationic antimicrobial polymerpolyhexamethylene guanidine hydrochloride and its mode of action. Fungal Biol. v. 121(1), p. 53-60, 2016.

CHOI H, LEE DG. Antifungal activity and pore-forming mechanism of astacidin 1 against Candida albicans. Biochimie. v.105, p. 58-63, 2014.

CIESIELSKI F, GRIFFIN DC, LORAINE J, RITTIG M, DELVES-BROUGHTON J, BONEV BB. Recognition of Membrane Sterols by Polyene Antifungals Amphotericin B and Natamycin, A (13)C MAS NMR Study. Front cell Dev Biol. v. 4(June) p. 57, 2016.

DEL PRINCIPE MI, SARMATI L, CEFALO M. A cluster of Geotrichum clavatum (Saprochaete clavata) infection in haematological patients: a first Italian report and review of literature. Mycoses. v. 59(9) p. 594-601, 2016.

DOUGLAS LM, KONOPKA JB. Plasma membrane organization promotes virulence of the human fungal pathogen Candida albicans. J Microbiol. v. 54(3) p. 178, 2016. 
FERNÁNDEZ-RUIZ M, GUINEA J, PUIG-ASENSIO M. Fungemia due to rare opportunistic yeasts: data from a population-based surveillance in Spain. Med Mycol. myw055, 2016.

GALVÁN MÁRQUEZ I, AKUAKU J, CRUZ I, CHEETHAM J, GOLSHANI A, SMITH ML. Disruption of protein synthesis as antifungal mode of action by chitosan. Int $\boldsymbol{J}$ Food Microbiol. v. 164(1), p. 108-112, 2013.

HUANG L, ZHANG J, SONG T. Antifungal curcumin promotes chitin accumulation associated with decreased virulence of Sporothrix schenckii. Int Immunopharmacol. v. 34, p. 263-270, 2016.

JI Q, GE Z, GE Z. Synthesis and biological evaluation of novel phosphoramidate derivatives of coumarin as chitin synthase inhibitors and antifungal agents. Eur J Med Chem. v. 108, p. 166-176, 2016.

KATHIRAVAN MK, SALAKE AB, CHOTHE AS. The biology and chemistry of antifungal agents: A review. Bioorg Med Chem. v. 20(19) p. 5678-5698, 2012.

KHAN N, SHREAZ S, BHATIA R, ET AL. Anticandidal activity of curcumin and methyl cinnamaldehyde. Fitoterapia. v. 83(3), p. 434-440. 2012.

LEE H, CHOI H, KO HJ, WOO ER, LEE DG. Antifungal effect and mode of action of glochidioboside against Candida albicans membranes. Biochem Biophys Res Commun. v. 444(1) p. 30-35, 2014.

LIN YY, SHIAU S, FANG CT. Risk factors for invasive Cryptococcus neoformans diseases: A case-control study. PLoS One. v. 10(3), 2015.

M. Chaudhary P, G. Tupe S, V. Deshpande M. Chitin Synthase Inhibitors as Antifungal Agents. Mini Rev Med Chem. v. 13(2), p. 222-236, 2013.

MEZZARI A, WLIEBBElling A. Criptococose em um Hospital Público de Porto Alegre: dados epidemiológicos. J Infect . v. 2(3) p. 135-139., 2013.

PATEL S, GOYAL A. Chitin and chitinase: Role in pathogenicity, allergenicity and health. Int J Biol Macromol. v. 97, p. 331-338, 2017.

PEMÁN J, QUINDÓS G. Current aspects of invasive diseases caused by Candida and other yeast fungi. Rev Iberoam Micol. v. 33(3) p.133-139, 2015.

RABELO VW, SANTOS TF, TERRA L. Targeting CYP51 for drug design by the contributions of molecular modeling. Fundam Clin Pharmacol. v. 2016, p. 37-53, 2016.

SAMBER N, KHAN A, VARMA A, MANZOOR N. Synergistic anti-candidal activity and mode of action of Mentha piperita essential oil and its major components. Pharm Biol. v. 53(10), p. 1496-1504, 2015.

SANT DG, TUPE SG, RAMANA C V., DESHPANDE M V. Fungal cell membrane promising drug target for antifungal therapy. J Appl Microbiol. v. 2016, p. 1-13, 2016. permeability and inducing oxidative stress. Biochim Biophys Acta - Biomembr. v. 1859(3) p. 467-474, 2017. 